\title{
El cuaderno escolar: prácticas escritas en el desarrollo del pensamiento social*
}

\author{
María Alejandra Taborda - Ruth Elena Quiroz Posada**
}

\section{Resumen}

El estudio del cuaderno escolar como tema clave de las preocupaciones didácticas, ha tenido un espacio accesorio, relacionado hoy día con mecanismos que dificultan, reproducen, limitan o innovan la cotidianeidad escolar; esto es, la evidencia privilegiada de la interacción entre el profesor y el estudiante, los contenidos, los procedimientos y las actitudes, y adicionalmente, ha sido un vínculo por excelencia de la escuela con la familia.

El cuaderno es un instrumento o dispositivo escolar para hacer seguimiento, verificar el desarrollo intelectual, detectar dificultades de aprendizaje, corregir ortografía, percibir errores conceptuales, chequear consultas, entre otros. Tanto se han desarrollado esta herramienta, que en el mercado algunos cuentan con Certificación ISO 9002, en relación con su uso dentro de la enseñanza de las Ciencias Sociales. A raíz de ello, surgió la pregunta por la potencia didáctica del cuaderno de Ciencias Sociales, su lugar en la comprensión de una cultura escolar y el tipo de pensamiento social que se infiere en él. Una primera aproximación a este objeto de estudio, está orientada a

\footnotetext{
* Artículo recibido el 19 de Abril de 2016. Aceptado el 1 de Julio de 2016.

** María Alejandra Taborda, Doctora en Educación por la Universidad Pedagógica Nacional, Docente de la Universidad de Córdoba (Colombia) alejandrata67@yahoo.com. Ruth Elena Quiroz Posada, Doctora en Ciencias Pedagógicas, docente de la Universidad de Antioquia (Colombia) rquiroz.udea@gmail.com.
} 
De Prácticas y discursos/ Universidad Nacional del Nordeste/ Centro de Estudios Sociales

delimitar los abordajes teóricos posibles y a plantear problemas con miras a abrir futuras líneas de investigación.

Sin embargo los resultados preliminares que mostramos aquí hacen parte de una investigación mayor referida a la cultura escolar y el uso de las imágenes dentro de la didáctica de las ciencias sociales que se viene desarrollando con la Red Geografía e Imagen en la que participan ocho universidades brasileras, y la Universidad de Buenos Aires. La metodología es de corte descriptivo e interpretativo.

\title{
Palabras clave
}

Cuaderno, didáctica, Ciencias sociales.

\section{The school notebook: written practices in the development of social thought}

\begin{abstract}
The study of the school notebook as a key issue of educational concerns, has had an unimportant role, related with the mechanisms that make it difficult, provide opportunities, limit or innovate the daily school life nowadays; that is, the privileged evidence of the interaction between teachers and students, contents, procedures and attitudes. Added, it has been an essential link between the school and the family

The notebook is a school instrument or device to assess, evaluate proficiency, identify learning difficulties, correct spelling, identify conceptual errors, check notes, among others. It has developed so much that some of them have ISO 9002 Certification, concerning its use in the teaching of social studies. As a result, the question has arisen concerning the potential methodological role of the social studies notebook, its place in the understanding of a school culture and the type of social thoughts within it. A first approach to this
\end{abstract}


De Prácticas y discursos/ Universidad Nacional del Nordeste/ Centro de Estudios Sociales

object of study aims at defining the possible theoretical approaches and research problems aiming at the definition of possible upcoming research areas.

However, the preliminary results shown in this study are part of a larger research regarding the school culture and the use of images within the teaching of social studies that has been developed with the imagery and Geography Network, in which eight Brazilian universities and Universidad de Buenos Aires are involved.

\section{Keywords}

Notebook, educational, social sciences.

\section{Introducción}

El cuaderno escolar plantea interrogantes didácticos fascinantes respecto a la enseñanza y el aprendizaje de las Ciencias Sociales. Apenas hace una década este dispositivo comenzó a ser objeto de reflexión didáctica, aunque para algunos es posible registrar su origen en América Latina durante la segunda mitad del siglo XIX, a inicios de la producción del papel. Sin duda, esta herramienta escolar rica en subjetividades, tanto del profesor como del mismo estudiante, permite analizar la concepción de pasado y futuro, las competencias ciudadanas y la proposición de espacios y protagonistas a través del análisis de las prácticas escritas de los estudiantes de una forma contraria a la lo hacen los libros, que son sistemáticos ordenados y secuenciales. Los cuadernos reflejan los contenidos enseñados, como también la creatividad, los silencios, las iniciativas, las representaciones de los estudiantes con sus notas al margen y al final; se convierten hoy en la categoría por excelencia de los saberes y las disciplinas escolares(Quintero,2007)

Tan importante es la presencia del estudio de los cuadernos escolares como objetos museológicos, que en 2008 en Huesca, la Sociedad del patrimonio histórico educativo (SEPHE), organizó su tercer congreso internacional; ya en 2007 se había inaugurado 
De Prácticas y discursos/ Universidad Nacional del Nordeste/ Centro de Estudios Sociales

esta preocupación en Macerata con el primer congreso internacional sobre los cuadernos escolares (Sanchidrián y Gallego, 2013).

Para Brailovsky (2012), los cuadernos escolares se vinculan al mundo de la escuela en una doble dinámica: constituyen la esencia del mundo de los niños en la escuela, pues, por un lado, permiten describir representaciones, competencias, sentimientos y saberes escolares, a la vez que son expiraciones performativas de la misma cultura política y social. Este artefacto escolar también puede verse a través a través de dos dispositivos: violencia y el conflicto, y con la legitimización del conocimiento social, convirtiéndose así en un transmisor de ideología.

Por otro lado, existe la idea de que los cuadernos escolares aparecen como "criterios de autenticidad", lo que Chartier (2000) desarrolla a través del concepto de "haceres ordinarios" como la acción de lo que sucede efectivamente en las aulas, que habitualmente se invisibiliza en contradicción con los planes microcurriculares y los discursos didácticos sobre el deber hacer.

En concordancia con lo anterior, se requiere abordar el tema de los cuadernos como objeto de estudio para analizar el pensamiento social y los modos en que se estructuran las prácticas cotidianas de los sujetos que enseñan y aprenden, al tiempo que producen efectos sobre la cultura escolar ofreciendo evidencias para entenderla. De hecho, podrían convertirse en material curricular, dado que muestran realmente lo que se está enseñando en las aulas de clase.

Al ser el cuaderno un artefacto del mundo escolar se ha transformado en un mediador entre los conocimientos del profesor y la interacción de los estudiantes; estos contienen una fundamentación psicopedagógica, disciplinar y estética que no resulta desligada de las formas de enseñar y aprender, y que por ende debería llevarlos a ser vistos como producción de saberes, procedimientos, imágenes y gráficos desde el terreno que conforman los estudios sobre la escritura y la lectura del conocimiento social.

El escritor asiduo del cuaderno es el estudiante, el lector predilecto es el profesor y el observador más constante es el padre de familia; todos lo evalúan, desde diferentes 
De Prácticas y discursos/ Universidad Nacional del Nordeste/ Centro de Estudios Sociales

visiones. Existen otros lectores potenciales en la escuela, como psicólogos, pedagogos o administradores.

De otro lado, los estudios sobre cuadernos dentro de las Ciencias Sociales escolares, han sacado a la luz un campo de investigación rico y lleno de retos en el que sin duda se deben experimentar aproximaciones de índole transdisciplinario, estudiar la abundancia de imágenes (mapas, gráficos, dibujos, fotos, calcados, fotocopias) que se involucran con técnicas variadas de calidad expresiva, y además analizar las narraciones escritas en las que se configura, como en ningún otro espacio, el pensamiento social de los estudiantes como producto materializado de la enseñanza y la aprehensión de los procesos y las habilidades cognitivas que se producen en el proceso de aprendizaje.

Adicionalmente se tiene que en términos metodológicos este es un estudio de casos de corte descriptivo e interpretativo, que se constituye con información detallada para desarrollar categorías conceptuales o servir de sustento a ciertas formulaciones teóricas instauradas con anterioridad al proceso de recolección de datos que se compone de una muestra de 10 cuadernos de Ciencias Sociales de los grados quinto de primaria y noveno grado de secundaria, el lenguaje didáctico, los recursos expresivos y la maduración del pensamiento social que está inmerso en ellos, pueden proveernos algunas ideas.

Este documento se configura de una entrada de construcciones teóricas y epistemológicas del cuaderno escolar, seguida de un seguimiento a su configuración histórica, precisiones metodológicas e interpretación de cuadernos pertenecientes al área de las ciencias sociales. A continuación de desarrollará cada una de las siguientes enunciaciones

\section{Disertaciones conceptuales}

El estudio del cuaderno del estudiante ha venido desarrollándose especialmente desde finales del siglo pasado. Autores como Devalle y Perelman (1988), Gvirtz (1997) y Chartier (2005) evidencian sus posibilidades como campo de conocimiento pedagógico y didáctico, y aunque aún es inmadura, existe ya una base conceptual con la que se configura un saber. A ello se suma el que el cuaderno no es un objeto natural, tiene 
De Prácticas y discursos/ Universidad Nacional del Nordeste/ Centro de Estudios Sociales

una historia social y se construyó con no pocos conflictos de diferentes órdenes que dieron lugar a este particular dispositivo.

En América Latina uno de los primeros trabajos importantes en este campo provino de Devalle y Perelman (1988), quienes asumieron que el cuaderno de clase es un texto escrito que se comporta como dispositivo evaluador realizado por los estudiantes en la escuela; en él se observan cotidianamente los aprendizajes, permitiendo medir aspectos de lingüística, pedagogía, didáctica y psicopedagogía.

Se convierte pues en un documento oficial que da testimonio de una legalidad, de un seguimiento muy particular que lo diferencia de otros textos escritos dentro y fuera del aula. Para autores como Batallán (1986) los profesores se dirigen simultáneamente desde los cuadernos a condicionar las respuestas consideradas correctas, a disciplinar conductas y a homogeneizar saberes a través de la instrucción de los contenidos, sancionan su incumplimiento y hacen uso de estos como instrumento evaluador y de poder.

De otra parte, existen conductas para el uso de los cuadernos que se espera se interioricen; tal es el caso del control del cuerpo y de las manos frente a la postura de la escritura en los niños ya que no se debe escribir de cualquier modo.

Los estudios preliminares se iniciaron con Devalle y Perelman (1988) y los estudiaron desde su aspecto físico cómo expresiones de prolijidad, limpieza y armonía "no debe estar roto, descosido, sucio, manchado, ni borroneado; deben estar organizados como los textos impresos, por eso no se pueden dejar espacios en blanco, escribir en las márgenes, saltar hojas ni arrancarlas, sirven para testimoniar la tarea del aula" (p. 23). Así mismo, los padres deben leer sus comunicaciones, en ellos están las tareas las notas de los niños y las actividades por realizarse. Está prohibido, apuntan los mismos autores (1988) "copiarse del compañero sólo hay que copiarse del profesor, la mirada debe dirigirse a él. Salvo cuando se está enfermo, el cuaderno de un compañero sí puede ayudar", $(p, 7)$ desde esta óptica los estudios iniciales se referían a aspectos de forma

Desde otras perspectivas, Galván (2007) enfatiza que estos son fuentes asociadas a la vida cotidiana de los estudiantes de ayer y hoy, y prescriben el mundo de los saberes; por ello, se registran en largos procesos históricos. Asimismo, son parte de un grupo 
De Prácticas y discursos/ Universidad Nacional del Nordeste/ Centro de Estudios Sociales

significativo de historias que se escriben en papel, y que forman la cultura escrita de las escuelas de todos los tiempos, por ser estos los lugares en donde se producen. Pero tal vez lo más importante es la insistencia en recalcar que en ellos se encierran las memorias colectivas de un pasado que ha sido olvidado por la historiografía de la educación.

De igual forma, desde la sociología de la educación los cuadernos están, según Bordieu (2001), asociados con la "violencia simbólica" en la medida en que se comportan como un instrumento evaluador, lo cual implica que se valida como un ordenamiento de valores absolutos, un solo dialecto, un modo de presentación del contenido, ocultando así las diferencias sociolingüísticas y cognitivas de los niños, pudiendo favorecer la marginación de ciertos sectores sociales.

El potencial pedagógico del cuaderno escolar está en su uso y conviene hacer un recordatorio del análisis crítico que Bourdieu y Passeron (1977) realizaron de los instrumentos pedagógicos como elementos de control, homogenizados y homogeneizantes. A juicio de estos autores, el sistema educativo pone a disposición de los profesores, agentes educadores, una serie de instrumentos: manuales, diarios de campo, recursos nemotécnicos, libros, programas, instrucciones pedagógicas, etc. con el fin de garantizar una inculcación efectiva de la hegemonía cultural que se pretende reproducir.

Se abre entonces como objeto para mirar las relaciones de saber y poder. A partir de ahí, Trujillo (2007) sugiere dos tipos de cuaderno, cada uno fuera del otro: uno instituido, homogeneizante, presentado con orden e higiene, asumido como regla, y otro instituyente, como posibilidad de expresión, creatividad, búsqueda, comunicación, asumido como instrumento, siendo este el menos apreciado.

Los cuadernos escolares son portadores de huellas, mensajes, silencios ya que mantienen una correspondencia con la ideología, las subjetividades, los valores y las prácticas pedagógicas asociadas al profesor, al estudiante y al contexto en que fueron elaborados. Son los únicos objetos de la escuela capaces de mostrar lo que el profesor enseña en cada lección, ofreciendo una visión distinta a la que proporcionan el programa escolar y los libros de texto (Sanchidrián y Arias, 2013). 
Existen también los cuadernos de trabajo que son un complemento del texto escolar, con el cual conforma un conjunto didáctico ya que se relacionan y se integran, ayudan a ahorrar tiempo, y en lugar de copiar algunas actividades en sus cuadernos, los estudiantes pasan directamente a desarrollarlas en estos.

Vistos como dispositivos curriculares, los cuadernos, a juicio de Badanelli y Mahamud (2007), presentan escasa literatura, elemento que constituye un obstáculo para poder ubicarlos dentro del conjunto de materiales curriculares. Sin embargo, estos no dejan de ser medio, instrumento o soporte que facilita y potencia el proceso de enseñanza y aprendizaje en sus múltiples dimensiones y objetivos.

La abundancia de imágenes y la calidad expresiva e incluso técnica de muchas de ellos, constituye un registro visual que no deja de sorprender en referencia al contexto escolar de la época. La producción de imágenes aparece en doble función, según Fernández (2008:17), como "dispositivo didáctico, de alcance múltiple y como registro de las prácticas escolares" y extraescolares.

\section{El cuaderno: acontecimiento histórico}

El cuaderno fue inventado por el australiano Birchall, en 1920, quien fue el primero en unir varios papeles y pegarlos a un pedazo de cartulina, en lugar de usar un montón de hojas sueltas (Pedraza y Clemente, 2003).

Antes de la producción de los cuadernos la escritura se realizaba en papel suelto; se vendía en el siglo XIX en lotes de 24 que se alojaban en una caja que se conformaba como una resma de 20 cuadernillos. Este inconveniente en la forma de empacado y venta de papel, llevó a Birchall a sugerir a los famosos británicos fabricantes de papel Wiggins Teape, una idea más conveniente en la que se cortaba en hojas más pequeñas, se embalaba en un pedazo de cartón y se engomaba en la parte superior. La sugerencia se consideró indignante y fue rechazada de plano por los directores de la famosa compañía británica; sin embargo una vez salieron los primeros encuadernillados, su uso se masificó rápidamente.

En América Latina, hasta finales del siglo XIX, especialmente en Chile y Argentina, el papel era un artículo de lujo importado, pues se trataba de un recurso costoso para la 
De Prácticas y discursos/ Universidad Nacional del Nordeste/ Centro de Estudios Sociales

labor escolar . En 1884 se constituyó la primera fábrica de papel "La Argentina" la cual solo proveía de papel para diarios y embalaje. En Colombia, la escuela empleaba diversos tipos de recursos que eran más viables que el papel: la pizarrita manual y los cajones o mesas de arena. Había que esperar hasta los grados más avanzados de escolaridad para comenzar el proceso de aprendizaje de la escritura utilizando papel (Museo de las Escuelas, 2004).

Con la llegada del Movimiento "Escuela Nueva" las escuelas no habían unificado criterios de trabajo con el cuaderno y se utilizaban gran variedad de ellos: aritmética, caligrafía, escritura, apuntes, etc. Frente a esta multiplicidad, el cuaderno único se presentó como una novedad significativa (Museo de las Escuelas, 2004).

De igual manera, la llegada del taylorismo creó un isomorfismo entre escuela e industria; se debía responder más cabalmente al concepto de trabajo. Así, se convertiría el cuaderno en un instrumento para hacer "ejercicios" con la intención de acabar la escuela verbalista. Estos cuadernos ya no serían como los que se mostraban en las exposiciones de fin de año en el régimen escolar tradicional (Museo de las Escuelas, 2004).

Los maestros comenzaron a escribir fue en mesas de arena, luego en pizarras. Los estudiantes comenzaron a escribir fue cuando se les entregó hojas rayadas en las que convertirían en auténticos libros personalizados con el esfuerzo del aprendizaje diario, a través del copiado que el profesor les dictaba.

Desde otra perspectiva, Badanelli y Mahamud (2011) analizaron los cuadernos escolares como fuentes para la investigación en Historia de la Educación, con especial énfasis en la utilización de las imágenes como mecanismo para transmitir sentimientos y emociones, así como un recurso que apoyaba los mensajes de los textos; sin duda cada cuaderno muestra, entre otros aspectos, la formación de la mentalidad social de la época.

Para los años cincuenta, la fabricación de papel fue intensiva y más barata, y por tanto el cuaderno se convirtió en el instrumento escolar primordial de las salas de clases, en el que los estudiantes lograron plasmar la caligrafía, la aritmética, la geografía, la historia y la transmisión de la cultura. Finalmente se tiene que los cuadernos como 
De Prácticas y discursos/ Universidad Nacional del Nordeste/ Centro de Estudios Sociales

dispositivos escolares tienen una construcción histórica ligada a la invención del papel y la sistematización de la clase.

\section{El cuaderno: contrato didáctico con los estudiantes}

El cuaderno escolar de Ciencias Sociales además de funcionar como estimulador de la expresión del estudiante a través del dibujo de mapas, paisajes y personas, tiene evidentemente un papel que desempeñar más allá del uso depositario que inicialmente conlleva. No se pude restringir su estudio a la simple mirada de la escrituración de los saberes expuestos en él, ya que es el profesor quien determina lo que se debe hacer y de qué manera. Por ello, este dispositivo didáctico está cargado de emociones, intereses y preocupaciones que el estudiante toma del maestro y adapta a sus expectativas; en él, además, se puede evidenciar el nivel de aprehensión e interés por un discurso dado.

A través de este artefacto escolar el estudiante da respuesta a las indicaciones planteadas por el profesor, quien dentro de un mismo proceso, ingresa de nuevo como autor principal de la actividad del cuaderno al corregir y evaluar lo realizado por el estudiante. En lo concerniente a la manera como se introducen las Ciencias Sociales, en un estudio preliminar Londoño (2014) encontró, después de analizar un grupo de cuadernos, que el saber se presenta linealmente, puesto que los contenidos son desarrollados de manera aislada sin darse una secuencialidad entre éstos, es decir, argumenta que no existe una relación entre el tema que se está manejando y el que le precede.

Así mismo, Fernández (2008) arguye que la imagen dentro del cuaderno de Ciencias Sociales representa un discurso por sí mismo; existe un lenguaje y una intención en cada lámina, fotocopia o imagen, y por ello en los dibujos y las pinturas se aprecia una evolución de los contenidos.

Décadas atrás en el cuaderno se evidenciaba una gran variedad de técnicas expresivas con acuarelas y collages que ya no existen. Estos dibujos han servido para que los estudiantes interioricen más fácilmente determinados conceptos abstractos. Asimismo, 
De Prácticas y discursos/ Universidad Nacional del Nordeste/ Centro de Estudios Sociales

se hace necesario cotejar los cuadernos con la utilización de otras fuentes orales y otros libros diferentes al texto escolar.

Cada cuaderno, según Gvirtz (1998), se compone de un cúmulo de competencias personales y sociales del estudiante, vinculadas a un contexto histórico-educativo específico, en el que la escuela se pone al servicio del Estado. Son expresiones didácticas cargadas de información, sobre el tiempo, el currículum oculto, la organización y la vida escolar de los centros. A través de los cuadernos, también es factible recuperar la labor del profesor, los procedimientos y las actitudes propios del proceso de enseñanza y de los esfuerzos por el aprendizaje.

\section{Metodología desarrollada}

Se realizó una observación comparada de cuadernos escolares de diversos gados y lugares diferentes pertenecientes a contenidos de Ciencias sociales, para ello se realizó un estudio preliminar a manera de pilotaje en el que se desarrollaron estrategias de observación para determinar lo que se enseñanza y se aprende materializado en el cuaderno. De igual forma, se indagó el modo en que estos son capaces de conservar la memoria pedagógica, los temas de interés, la forma de enseñar de los profesores y la práctica diaria de los grupos escolares.

Uno de los propósitos fue analizar los cuadernos escolares como fuente para la interpretación de la Didáctica de las Ciencias Sociales y estudiar las formas y las maneras de la integración de estas ciencias a través del cuaderno.

Para esto fue necesario ubicar los cuadernos dentro del contexto al que pertenecen (escuelas públicas de carácter normalista de Córdoba y Medellín) durante 2015. Como fuente primaria inicial se utilizó una colección de diez cuadernos escolares.

Adicionalmente, se pudo observar información complementaria, como la expresión escrita e icónica del estudiante, desde la caligrafía, hasta los distintos tipos de actividades de transmisión de la cultura escrita: la copia, el dictado y la redacción individual y colectiva. Una vez designado su uso individual o colectivo y establecido el tipo de contenido se eligieron las diferentes prácticas de los conceptos: aplicados, copiados o interpretados (Badanelli y Mahamud, 2007). 
De Prácticas y discursos/ Universidad Nacional del Nordeste/ Centro de Estudios Sociales

El contenido de cada uno de los cuadernos fue minuciosamente desagregado en unidades por categorías para su estudio. Así, para cada cuaderno se describieron e interpretaron imágenes, textos, correcciones, encabezamiento, margen, anotaciones añadidas, evaluaciones, notas del profesor como lo sugieren Sanchidrián y Gómez (2013), en fichas en las que se indicó fecha, materia, procedencia, contenido, color y tamaño para realizar análisis cuantitativos y cualitativos de los mismos cruzando distintos ítems.

En relación con los métodos y para el estudio de los cuadernos, como fuente se usó la metodología trabajada por Blanco (2009) para establecer el tipo de pensamiento social integrado en los cuadernos, desde un estudio de contexto con una visión heurística que se ocupó de la localización y clasificación de los mismos.

\section{Análisis de los cuadernos escolares}

El análisis descriptivo e interpretativo de los primeros diez cuadernos mostró algunos elementos y significados, que no buscan realizar generalizaciones a partir de las observaciones efectuadas. En general se buscó realizar una mirada ideográfica, del cuaderno en profundidad, buscando que este utensilio escolar quedara claramente individualizado

\section{1 descripción de los cuadernos}

El tipo de cuadernos correspondió a una muestra de 10 cuadernos 3 argollados y 7 sencillos cocidos, todos ellos plastificados, 4 de tamaño grande y 3 pequeños, rayados de 50 hojas y línea corriente de 100 o 200 páginas. Todos eran rayados, de las marcas Norma, Scribe, Zeppelin, Impresarte y Grade. Corresponderían a estudiantes entre quinto, cuarto y noveno grado. , los cuadernos analizados corresponden a los contenidos de Ciencias Sociales del año 2015.

La calidad de los cuadernos se consideró fina, si bien en 8 de ellos se notó ausencia de hojas. Tenían anotaciones que hacían referencia a eventos, notas personales, apuntes de trabajos posteriores o comentarios sueltos en la contraportada. 


\subsection{Elementos estéticos de los cuadernos}

Las portadas del grado $5^{\circ}$. Son más coloridas y ricas en imágenes, en tanto que las del grado $9^{\circ}$. Son más sobrias, aún con colores pero con menos cantidad de imágenes. Están compuestos en su mayoría por imágenes de animales y calcomanías de princesas, mapas mudos y talleres fotocopiados por el profesor pegado al interior. Se ven como una copia del texto guía y hay preocupación por lo estético.

\subsection{Elementos del contenido}

Se observó bonito trazo y legibilidad de la caligrafía. Fue mayor la presencia de la Historia frente a la Geografía o a las Ciencias Sociales integradas. Se observó un esquema que se repite en cada sesión. No siempre se presentan los objetivos ni el método que se trabajó en cada una de ellas, así como tampoco hay mucha sistematicidad en los contenidos. Algunos dibujos al margen indican apatía o aburrimiento. Se presentan búsquedas en la Internet y pequeñas reflexiones. Se enseña mediante ejes temáticos y un texto guía de alguna editorial prestigiosa que no se reseña. Se observa que el interés del estudiante depende del tema con más información e imágenes.

\subsection{Elementos de evaluación}

Se nota una valoración del orden y la limpieza, al igual que una periodicidad recurrente en su calificación al terminar cada periodo; ocasionalmente se revisa ortografía. A veces se incluyen indicadores de desempeño. El profesor revisa o asigna notas en cada inicio de periodo (Segundo, tercero y cuarto)

\subsection{Estudio de los contenidos}

Se atendió al manejo considerando tiempos, contenidos, tareas, estrategias, horarios.

- Interés temático

- Apuntes del profesor

- Análisis de la vida escolar

- Valoración del cuaderno como instrumento pedagógico. 
De Prácticas y discursos/ Universidad Nacional del Nordeste/ Centro de Estudios Sociales

- Mayor observación de copia y dictado que de redacción libre

- Cantidad de ilustraciones bajadas de la Internet.

- Pocas narraciones inventadas fruto del esfuerzo del estudiante.

Los contenidos del grado noveno según los cuadernos analizados fueron los siguientes:

Cultura global. Eje temático: relaciones ético-políticas

- Cuestionario noticia y opinión.

- Indicadores

- Vocabulario

- $\quad$ Líder del siglo XXI

- Cambios generados en el siglo XX en la última década

- Ley 115 de los 94 organismos complementarios: Consejo de Padres, personero, consejo de estudiantes, contraloría escolar.

- Constitución colombiana de 1991

- Congreso de Colombia. Veeduría ciudadana, formas de participación.

- División del poder legislativo, ejecutivo y judicial.

- Actividad de indagación: Raza negra en el continente americano, origen del hombre americano, mapa de América ubicando la presencia de esta raza en el continente.

- $\quad$ Actividad: costumbres y alimentos de los negros, responsabilidades y deberes. Construcción de una Colombia mejor.

Eje temático: relaciones económico-sociales

- Elevación del nivel de vida de los colombianos.

- Crisis económica del país.

- $\quad$ Algunos problemas que afectan la economía del país.

- $\quad$ Actividad sobre la identidad personal conciencia y autorreconocimiento.

- $\quad$ Reflexiones personales ante el conflicto. 
De Prácticas y discursos/ Universidad Nacional del Nordeste/ Centro de Estudios Sociales

Los contenidos del grado quinto según los cuadernos analizados fueron:

Eje temático: gobierno escolar y derechos humanos

- $\quad$ Origen de la democracia

- $\quad$ El líder

- $\quad$ Ley $115 / 94$

- $\quad$ El gobierno escolar y su finalidad

- Órganos principales

- Objetivos funcionales y perfil del aspirante a representante de grupo, personera estudiantil y contralora.

- Derechos humanos y Constitución política de Colombia.

- Derechos humanos de $1^{\mathrm{a}}, 2^{\mathrm{a}}, \mathrm{y} 3^{\mathrm{a}}$ generación.

- $\quad$ Organismos que promueven y protegen los derechos humanos.

- $\quad$ Origen del hombre colombiano

- Accidentalidad y causas de la seguridad vial

Eje temático: vigencia de los derechos humanos

Los derechos de la condición humana y el respeto por la diversidad.

- Las mujeres y la construcción de equidad y respeto.

- Las relaciones socio-económicas.

- $\quad$ Preguntas problematizadoras: Video sobre la discriminación laboral de la mujer. Consulta de mujeres actuales importantes. Trata de personas y prostitución. Machismo. La mujer doblemente discriminada.

- $\quad$ Minicartelera sobre la mujer.

- $\quad$ Actividades sin realizar (crucigrama)

Grandes conflictos

- Afrocolombianidad

Eje temático: relaciones con la historia y las culturas

- Sabores culturales, conquistas y desafíos.

- Revoluciones en América y Europa y sus implicaciones en tiempos posteriores.

- Democracia, derechos humanos y solución del conflicto. 
- Vocabulario.

- $\quad$ Distribución del poder en el mundo.

- Cuadro. Categoría, denominación, características países.

- $\quad$ Primera Guerra mundial.

- Segunda. Guerra mundial.

- Consulta de siglas.

- Recurso natural, manejo, explotación, zonas agrícolas, industriales y ganaderas de Colombia.

- Tipos y formas de explotación.

- La población colombiana.

- Documentos del vehículo.

- $\quad$ Seguridad en el vehículo.

- Afrocolombianidad.

- $\quad$ Llegada del hombre Afro a américa.

- Mapas sin títulos, vacíos en el cuaderno.

La colonia en su organización social y política

- Tipos de organización en el periodo de la Colonia

- La independencia y la naciente República

- La Gran Colombia y los estados soberanos

- Época colonial y primera mitad del siglo XX

- Muchas fichas de trabajo fotocopiadas sobre la historia de Colombia.

Se concluye al cotejar el texto escolar con el cuaderno que guarda una relación directa en cuanto a los temas a tratar, la copia y desarrollo permanente de las tareas asignadas por los textos, no hay una secuencialidad temática ni tampoco una coherencia entre un tema que se deja con otro que se inicia, adicionalmente se encontró pocos apuntes de explicaciones realizadas por el maestro. 
5.6 El manejo de las imágenes en los cuadernos: Mas allá de temáticas escritas, los cuadernos escolares de ciencias sociales se componen de un grupo importante de imágenes, compuestos por mapas, dibujos, graficas, y láminas. En general la revisión de los cuadernos evidencio que el niño y el joven no dibujas ni realiza gráficos, buena parte de la imagen la encuentra lista para ser incorporada al cuaderno, disminuyendo la posibilidad de exploración estética de otras épocas. A continuación se observara lo anteriormente afirmado en la muestra de cuadernos de dos grado quinto de primaria y noveno grado.

\subsubsection{Cuaderno de un estudiante de quinto de primaria.}

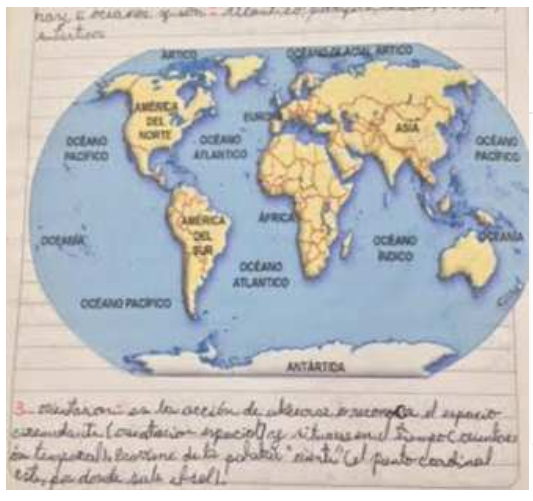

En la imagen se nota como el dibujo pierde el rol protagónico de otro tiempo, y la fotocopia de imáaenes del texto entra al cuaderno escolar, una característica recurrente en toda la observación.

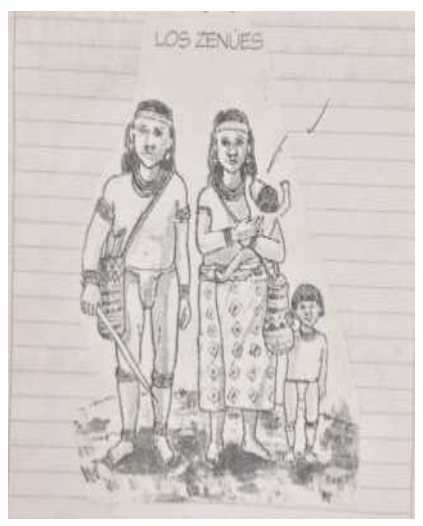

La única referencia encontrada a los grupos indigenas es esta imagen. No hay contenido ni reflexión que la acompañe, un contenido que no volverá a ver el niño hasta su próximo grado. El tema que le antecede son los tipos climáticos y los que le precede es la colonia como etapa histórica. 


\subsubsection{Cuaderno de un estudiante de noveno grado.}

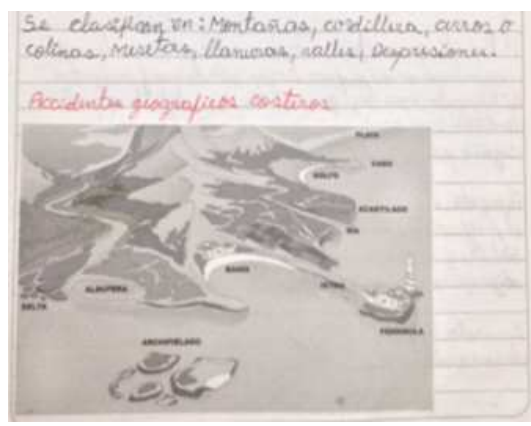

En este ejemplo se abserva como los conceptos y las imágenes del texto əscola. obsérvese en este ciladerno la fecha en día $y$ hora del contenido programático dado, y la manera como e niño resalta con rọo las ideas principales del texto cue copia

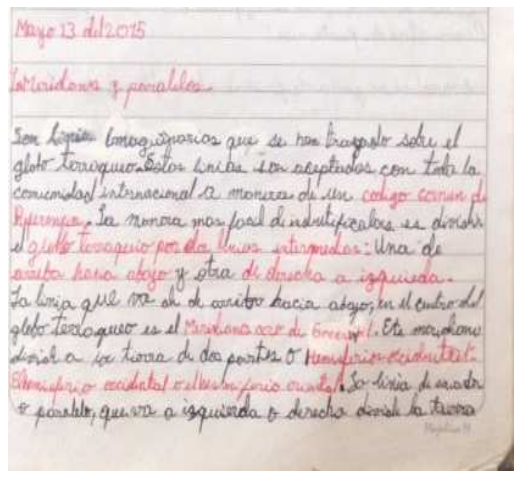

Obsérvese en este mismo cuaderno la fecha en día y hora del contenido programático dado, y la manera como el joven resalta con rojo las ideas principales del texto que copia. También se utiliza la fotografía, como posibilidad para estudiar la historia regional. Nótese el cuidado y la atención del niño, para integrar tiempos de antes.

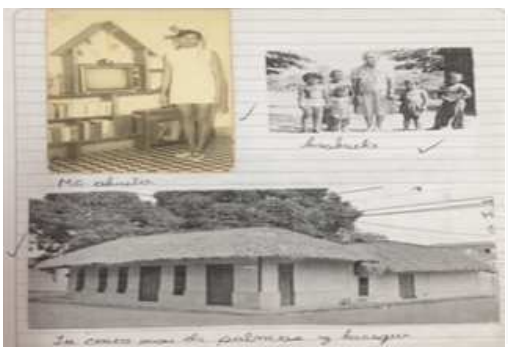

La abuela joven y tiempos de hoy, la abuela con los niños de la mano en este sentido una imagen dentro del cuaderno deja ver toda una construcción de la categoría tiempo.

\section{Un cuaderno de un estudiante de noveno grado}



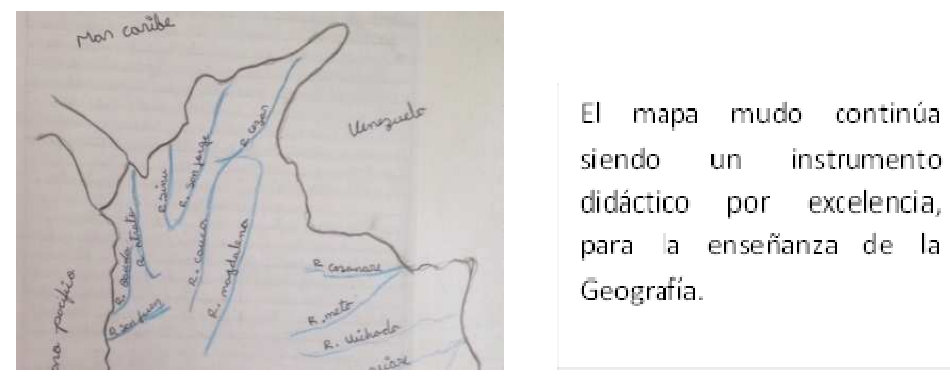

Los cuadernos resultaron iguales en contenidos, hecho que indica que se copia o se hace dictado. Los elementos, la forma de distribución, los colores y las estéticas si son diferentes. Así mismo, los compromisos y las tareas por su profundidad, nivel y acercamiento al tema con imágenes, dibujos, copias o búsquedas de información difieren de acuerdo con el interés de cada estudiante.

\subsection{Ideas conclusivas}

El proceso de construcción del conocimiento social visto inicialmente en 10 cuadernos escolares, muestra la práctica recurrente de reproducir el texto escolar o libro guía en el cuaderno, muy a pesar de la posibilidad que tiene el estudiante de primaria de comprender e interpretar con sentido los temas tratados. El conocimiento no se produce de forma individual o aislada. Los temas se presentan de manera lineal y desconectada, sin una forma lógica desde la Geografía, la Historia o las Ciencias Sociales.

En el cuaderno no hacen presencia las condiciones sociales que configuran el contexto social del que el estudiante se impregna o de la comunidad a la que pertenece; se parte del estudiante y de su familia pero no se trasciende al estudio del territorio. Tampoco está cargado de las normas, valores y fuentes de donde se obtiene las informaciones, elemento relevante dado que estas serán las que tome como referencia para elaborar sus propias explicaciones sobre la realidad. Es un cuaderno pensado para agradar al profesor porque él evalúa la limpieza, el orden y la estética. Finalmente, no existen espacios para la reflexión, la crítica y las posturas diferentes de 
De Prácticas y discursos/ Universidad Nacional del Nordeste/ Centro de Estudios Sociales

transformación de su medio, de su ambiente y de su vida como sujeto social que evoluciona y se apropia de su territorio para modificarlo y transformarlo.

A Futuro estas investigaciones nutren un campo en emergencia denominado historia de los saberes escolares en el que la cultura escolar se compone de las prácticas cotidianas que los niños realizan y que son de poco interés para la investigación pedagógica tradicional, entre otros temas, el descanso, la tarea el cuaderno escolar. Este estudio finalmente nos permite una comprensión más amplia del mundo escolar con sus tipificaciones, la escuela más allá del aprender y del enseñar.

Agradecimientos: Especiales a los estudiantes de la universidad de Córdoba, programa Licenciatura en Educación Básica con Énfasis en Ciencias Sociales Camilo Jhosuath, Petro Martínez y Luis Gabriel Mesa Pozo y a Juliana Araque Quiroz, de la Universidad de Medellín por la recolección y fotografía de los cuadernos utilizados en este estudio.

\section{Bibliografía}

Asensi, J. D. (2013) Estudio de una localidad en dos cuadernos escolares de 19461947. Revista Cabás n9 -100 Extraído desde: http://revista.muesca.es Fecha de consulta: enero 22 de 2016.

Badanelli, A y Del Pozo A. M. (2008). Desde la madre-patria española al estado de las autonomías. Historia de la Educación, 27, 397-432.

Badanelli, A. y Mahamud, K. (2007). Posibilidades y limitaciones del cuaderno escolar como material curricular. Un estudio de caso. Revista de la asociación de inspectores de Educación de Madrid: Avances en supervisión educativa. No. 5. 79-90. 
De Prácticas y discursos/ Universidad Nacional del Nordeste/ Centro de Estudios Sociales

Batallán, G.; Saleme, M. y García, R. (1986). El mundo del niño y su aprendizaje escolar. Incidencia en la reformulación del rol docente. Informe final. Buenos Aires: Flacso.

Birchallsh (2007). Our history Extraído desde: http://www.birchalls.com.au/index.php/about-us-mainmenu-133/our-historymainmenu-41. Fecha de consulta: diciembre 17 de 2015.

Bourdieu, P. (2001). La reproducción. Elementos para una teoría del sistema de enseñanza. Madrid, Editorial Popular.

Bourdieu, P. y Passeron, J. (1977). La reproducción. Barcelona: Laia.

Chartier, A.M. (2005) "Los cuadernos escolares en Francia". Ponencia presentada en el VIII congreso Internacional Historia de la Cultura Escrita. Alcalá de Henares, España.

Chartier, A.M. (2000). Fazeres ordinarios da classe: uma aposta para a pesquisa e para a Formacao. Educacao e Pesquisa, 26, 2, 157-168.

Cordero, I. y López, E. (1997-1998). La guerra en la escuela: cuadernos escolares de los alumnos de la Escuela Nacional de Oseja en los picos de Europa. Universidad de Huelva. Revista de historia contemporánea, 8, 159-180.

Devalle R. y Perelman S. (1988) ¿Qué es el cuaderno de clase? Revista Argentina de educación. 6, 10, 30-45.

Fernández, M. (2008). Los cuadernos escolares de la escuela Serena: un recorrido a través de sus imágenes (Rosario 1935-1950) Revista de la Escuela de Ciencias de la Educación 4, 3, 343-355.

Galván, L. E. (2007). Un cuaderno escolar en el mundo de los saberes mexicanos: 1919 IX. Congreso Nacional de Investigación Educativa. Extraído desde: http://www.comie.org.mx/congreso/memoriaelectronica/v09/. Fecha de consulta: enero 23 de 2016.

García, J. (1996). El cuaderno de seguimiento. Cuadernos de Pedagogía, 244, 1719.

Gimeno, J. (1991). El currículum: una reflexión sobre la práctica. Madrid: Morata.

Gvirtz, S. (1998). Del currículum prescripto al currículum enseñado. Una mirada a los cuadernos de clase. Buenos Aires: Aique. 
De Prácticas y discursos/ Universidad Nacional del Nordeste/ Centro de Estudios Sociales

Londoño, M, Herrera L. y Gutiérrez I. (2007). Análisis de cuadernos escolares de Ciencias sociales en los grados segundo y tercero de primaria. Investigación terminada. Pereira: Universidad Tecnológica de Pereira.

Museo de las Escuelas. (2004). Genealogía del cuaderno escolar. Extraída desde: http://www.buenosaires.gob.ar/areas/educacion/programas/me/pdf/gen3_cuadernoesc olar.pdf

Pedraza, J., Clemente, Y. y De los Reyes, F. (2003). El libro antiguo. Madrid: Síntesis. 168

Quiroz. R. y Díaz, J. (2011) Ámbitos de investigación de los textos escolares en la enseñanza de las Ciencias Sociales. Revista Uni-pluri/versidad, Medellín, Colombia. 11, 1,49-57.

Quintero Martha Elena (2007) Investigación de los Saberes Pedagógicos Extraída desde:http://www.mineducacion.gov.co/1621/articles208800_archivo_pdf_libro2.pdf

Sanchidrián, C. y Arias, B. (2013). La construcción de la identidad nacional española a través de los cuadernos escolares (1957-1959). Revista de Investigación Educativa, 31 (1), 257-274. Extraída desde: http://dx.doi.org/10.6018/rie.31.1.148661

Trujillo, A. (2007). Apatía, subjetividad y cuaderno escolar. Revista Nodos y Nudos 3, $22,81-93$. 